Check for updates

Cite this: RSC Adv., 2017, 7, 35805

\title{
Photosensitive bent-core liquid crystals based on methyl substituted 3-hydroxybenzoic acid †
}

\author{
Michal Kohout, (D) *a Mohamed Alaasar, (DD bc Anna Poryvai, ${ }^{\text {b }}$ Vladimíra Novotná, (D) d \\ Silvio Poppe, ${ }^{\mathrm{b}}$ Carsten Tschierske (D) ${ }^{\mathrm{b}}$ and Jiři Svoboda ${ }^{\mathrm{a}}$
}

Photosensitive liquid crystals are of contemporary interest not only from the scientific point of view but also for various applications. Herein we report the first photosensitive materials based on laterally substituted 3hydroxybenzoic acid. The molecular self-assembly of these new materials was characterized using different physical techniques including differential scanning calorimetry (DSC), X-ray diffraction (XRD) measurements, electro-optical investigations and dielectric spectroscopy. We show that the number and position of azo units with respect to the lateral substitution on the molecular core significantly influence mesomorphic properties of the materials. Based on the position of the substituent, either non-polar or polar smectic $\mathrm{C}$ phases are formed. The optimum combination of both the structural elements results in an achiral material which shows a broad polymorphism and exhibits a stable dark-conglomerate crystalline phase with macroscopically chiral domains at room temperature. The structure of this phase differs from the previously described fluid sponge-like distorted smectic phases as well as from helical nano-filament phases, thus, adding new information on the possible variations in the nanostructures of this kind of phase. Moreover, the photosensitivity of these materials has been studied using ${ }^{1} \mathrm{H}$ NMR spectroscopy.

\author{
Received 18th May 2017 \\ Accepted 12th July 2017 \\ DOI: 10.1039/c7ra05632j \\ rsc.li/rsc-advances
}

One of the most successful motifs in the search for light tuneable BCLCs represents resorcinol central core, which is extended with azo group-containing elongating side arms. First materials based on non-substituted resorcinol central core were either crystalline or exhibited only thermally unstable columnar mesophases. ${ }^{\mathbf{1 4 - 1 6}}$ The real breakthrough in the area of photosensitive BCLCs has arrived with the introduction of a lateral substituent on the resorcinol central core. It has been shown that a cyano group in position four of the central resorcinol ring triggers the formation of $\mathrm{SmC}_{\mathrm{S}} \mathrm{P}_{\mathrm{R}}$ (synclinic tilted smectic $\mathrm{C}$ phase with randomized polar order), which is capable of mirror symmetry breaking. ${ }^{17-19}$ Using a halogen as the substituent, a variety of dark conglomerate (DC) mesophases has been observed, in particular, for larger substituents such as bromine and iodine. ${ }^{\mathbf{2 0 - 2 2}}$ Replacing one azo group in the molecular structure with an ester unit provided materials whose mesomorphic behaviour depended on the orientation of the ester unit as well as on the position of the halogen substituent with respect to the remaining azo group. ${ }^{23}$ Apart from the polar electron-withdrawing substituents, also a weak electron donating methyl group has been introduced on the resorcinol central core to form materials with stable DC phases. ${ }^{24}$

Unlike the resorcinol derivatives mentioned above, compounds based on 3-hydroxybenzoic acid have been studied much less. The majority of the reported materials possessed one azo group in the molecular structure and exhibited columnar $\mathrm{B}_{1}$, lamellar $\mathrm{B}_{2}$ or a modulated smectic $\mathrm{B}_{7}$-type mesophases. ${ }^{\mathbf{1 4 2 5 , 2 6}}$ Related materials with two azo groups have been found to be

\footnotetext{
Department of Organic Chemistry, University of Chemistry and Technology Prague ${ }^{b}$ Institute of Chemistry, Martin Luther University Halle-Wittenberg, Kurt-Mothes Str. 2, Halle-Saale, D-06120, Germany

${ }^{c}$ Department of Chemistry, Faculty of Science, Cairo University, Giza, Egypt

${ }^{d}$ Institute of Physics, Academy of Science of the Czech Republic, Na Slovance 2, 18221 Prague 9, Czech Republic

$\dagger$ Electronic supplementary information (ESI) available: Synthesis and characterisation of materials, details on mesomorphic behaviour and photo-isomerisation measurements. See DOI: 10.1039/c7ra05632j
} 
non-mesogenic. ${ }^{15}$ Despite the fact that BCLCs based on 3hydroxybenzoic acid substituted in position four with all-ester side arms provided thermally more stable mesophases than the corresponding resorcinol-based analogues, ${ }^{27}$ no material based on laterally substituted 3-hydroxybenzoic acid has been reported yet. Additionally, the intrinsic non-symmetry of 3hydroxybenzoic acid central core determines different effect of the lateral substituent on the central core. Recently, it has been shown that the presence of a larger substituent in position six of the central 3-hydroxybenzoic acid unit reduces the flexibility of derived BCLCs leading to crystalline substances. ${ }^{28}$ On the other hand, the presence of a larger substituent and the reduced conformational flexibility has recently been recognized as an important feature for BCLCs forming DC phases..$^{13,21,23,24,29}$

In this contribution, we report the effect of the lateral substituent and its location on the mesomorphic properties of the new class of photosensitive BCLCs possessing one or two azo groups in their structure. We have also varied the position of the substituent with respect to the azobenzene wing, which results in a material exhibiting rich polymorphism.

\section{Experimental}

\section{Synthesis}

The synthesis of the new BCLCs under investigations is shown in Schemes 1 and 2 . The protected central units 1-4 were prepared from commercially available starting materials in accord with previously reported methods. ${ }^{27,28}$ The elongating side arms were synthesised by known synthetic procedures. ${ }^{18,30,31}$

A $N, N^{\prime}$-dicyclohexylcarbodiimide (DCC)-mediated esterification of protected acids 1 and 2 with corresponding phenols 5 and $\mathbf{6}$ in the presence of $N, N$-dimethylaminopyridine (DMAP) as catalyst gave rise to protected derivatives 7 and $\mathbf{8}$, respectively (Scheme 1). Based on the character of the silyl $\left(\mathrm{PG}=\left(\mathrm{CH}_{3}\right)_{3^{-}}\right.$ $\left.\mathrm{CSi}\left(\mathrm{CH}_{3}\right)_{2}\right)$ and benzyl ( $\mathrm{PG}=\mathrm{C}_{6} \mathrm{H}_{5} \mathrm{CH}_{2}$ ) protecting groups (PG), deprotection was achieved by tetrabutylammonium fluoride trihydrate $\left(\mathrm{TBAF} \cdot 3 \mathrm{H}_{2} \mathrm{O}\right)$ and transfer-hydrogenation with ammonium formate in the presence of palladium on charcoal, respectively. In the final step, the isolated hydroxy esters $\mathbf{9}$ and $\mathbf{1 0}$ were acylated with acid chlorides $\mathbf{1 1}$ and $\mathbf{1 2}$ of the second lengthening arm to yield the target materials of the series I.

Similarly as above, the protected central cores $\mathbf{3}$ and $\mathbf{4}$ were esterified in a DCC-mediated reaction catalyzed with DMAP to yield protected intermediates 13 and 14. Subsequent deprotection performed with respect to the used protecting groups provided hydroxy esters 15 and 16, acylation of which afforded the target materials of the series II (Scheme 2). The analytical data and the synthetic details for the intermediates as well as for the final BCLCs are summarized in the ESI $\dagger$ file.

\section{Experimental methods and set-up}

The phase transition temperatures and corresponding enthalpies were determined by differential scanning calorimetry (DSC), namely Pyris Diamond Perkin-Elmer 7 calorimeter was utilized. The samples of about 2-5 mg were sealed into aluminium pans, which were put into the calorimeter chamber filled with nitrogen.
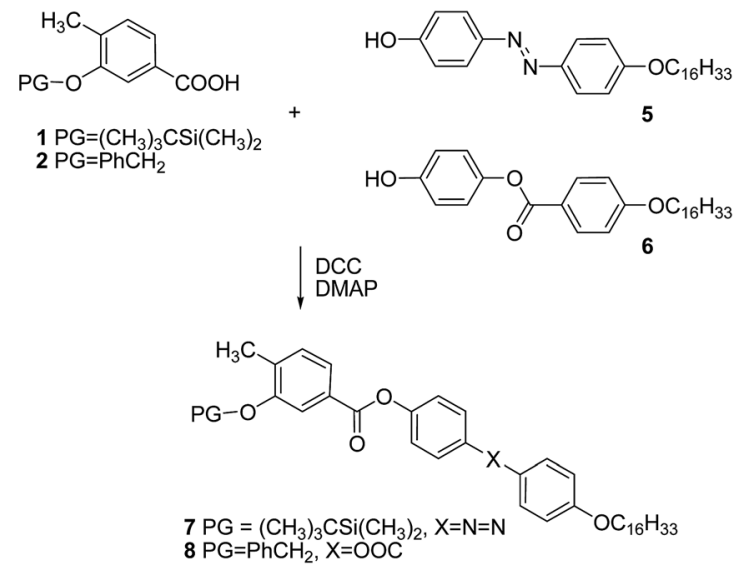

for 7 for 8

$\mathrm{TBAF} \cdot 3 \mathrm{H}_{2} \mathrm{O} \downarrow \downarrow$ for $8 \mathrm{HCONH}_{4}, \mathrm{Pd} / \mathrm{C}$
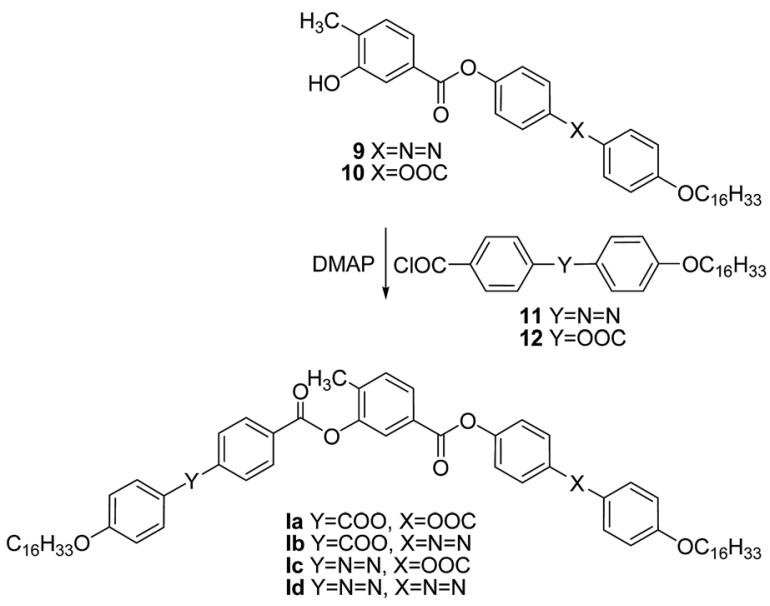

Scheme 1 Synthesis and designation of compounds of series I.

The temperature and enthalpy values were calibrated on the extrapolated enthalpy values of the melting points for water, indium and zinc. All calorimetric measurements were performed on cooling/heating runs at a rate of $5 \mathrm{~K} \mathrm{~min}^{-1}$.

The textures were observed under the polarizing optical microscope Nikon Eclipse E600. The cells for texture observation and electro-optical studies were made from glasses with ITO transparent electrodes $\left(25 \mathrm{~mm}^{2}\right)$, separated by mylar sheets defining the cell thickness. No glass-surface treatment was utilized. The cells (usually $3 \mu \mathrm{m}$ thick) were filled with studied compounds in the isotropic phase by the capillary action. Another sample can be prepared by spreading the droplet in the isotropic phase on the glass surface (one-free-surface sample). The Linkam LTS E350 heating/cooling stage with TMS 93 temperature programmer was used for the temperature control. The stabilization of the temperature was within $\pm 0.1 \mathrm{~K}$. The electro-optical switching characteristics were studied with the triangular-wave method using a home-made set-up in $6 \mu \mathrm{m}$ polyimide coated ITO cells, EHC Japan. Voltage of $100 \mathrm{~V}_{\mathrm{pp}}$ at a frequency $10 \mathrm{~Hz}$ and resistor $5 \mathrm{k} \Omega$ were utilized.

Dielectric properties were studied using Schlumberger 1260 impedance analyser. Measurements were performed on cooling and the temperature was stabilized during the frequency 


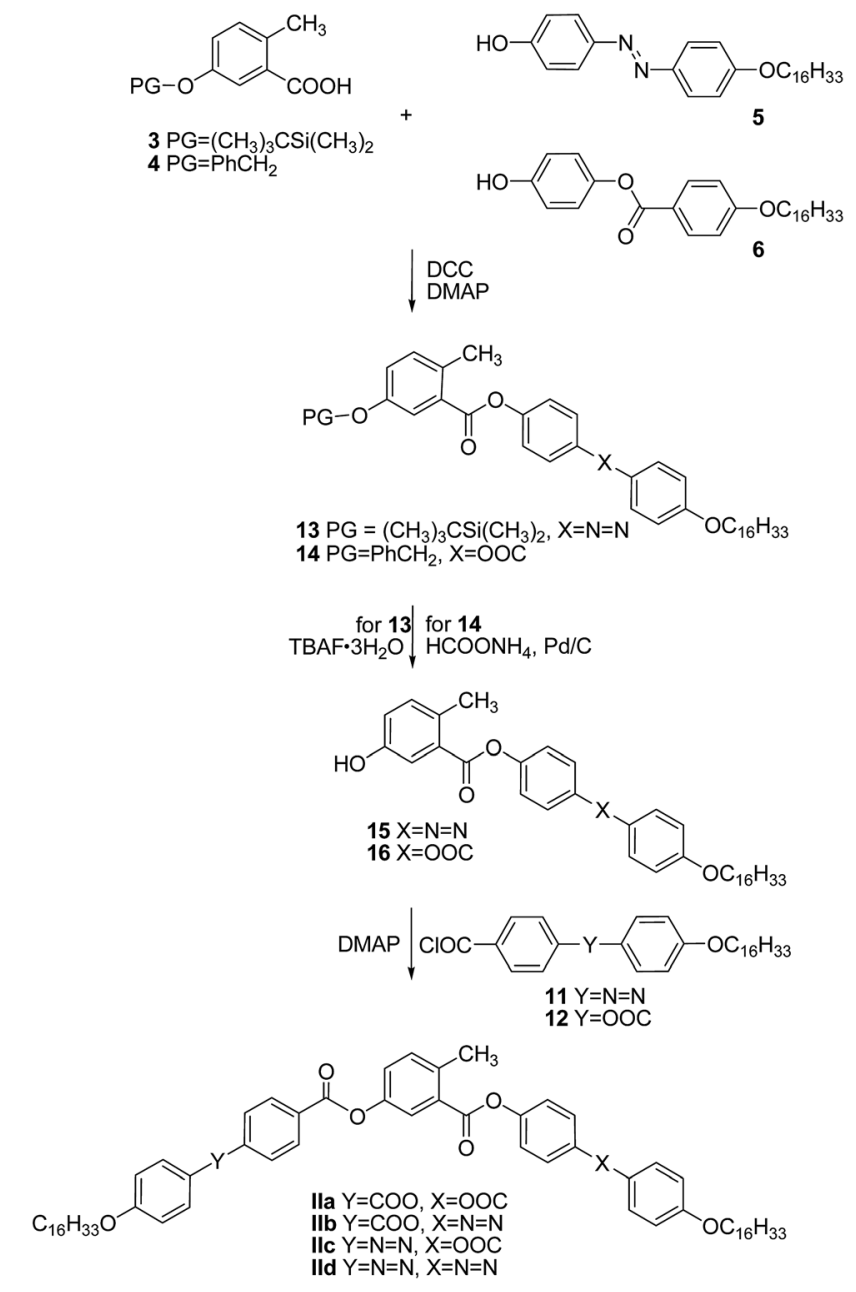

Scheme 2 Synthesis and designation of compounds of series II.

sweeps in the range of $10 \mathrm{~Hz}$ to $1 \mathrm{MHz}$. The frequency dependent complex permittivity $\varepsilon^{*}=\varepsilon^{\prime}-\mathrm{i} \varepsilon^{\prime \prime}$, namely the real, $\varepsilon^{\prime}$, and the imaginary, $\varepsilon^{\prime \prime}$, parts were detected in a broad temperature range on cooling from the isotropic phase.

X-ray diffraction patterns were recorded with a 2D detector (Vantec 500, Bruker). Ni filtered and pin hole collimated $\mathrm{CuK}_{\alpha}$ radiation was used. The exposure time was $30 \mathrm{~min}$ and the sample to detector distance was $8.95 \mathrm{~cm}$ and $26.7 \mathrm{~cm}$ respectively. Uniform orientation was achieved by alignment at the airsample interface on top of a small droplet. The samples were held on a temperature-controlled heating stage.

Photochemical properties were studied using Agilent $400 \mathrm{MR}$ DDR2 spectrometer. The selected compounds were dissolved in deuteriochloroform and irradiated at $365 \mathrm{~nm}$ with a common laboratory UV lamp for $8 \mathrm{~h}$. The samples were placed into an NMR instrument tempered at $50{ }^{\circ} \mathrm{C}$ and the spectra were acquired with $700 \mathrm{~s}$ steps between measurements, duration of each measurement was $57 \mathrm{~s}$.

\section{Results and discussion}

Based on the position of lateral substituent (methyl group) on the central core, the materials were divided into two series: 4- substituted compounds are denoted as series I and 6substituted compounds are denoted as series II (see Schemes 1 and 2). The mesomorphic behaviour of the studied materials was determined from thermal behaviour obtained by DSC, texture observation under the polarizing optical microscope and electro-optical behaviour under the applied electric field (Table 1). To support the phase identification, X-ray measurements were performed for a selected example.

\section{Series I}

Compound Ia with all-ester linkages exhibited a monotropic $\mathrm{SmC}_{\mathrm{s}}$ phase. The introduction of an azo group in the elongating side arm connected to the carboxylic unit of the central core (Ib) led to an interesting polymorphism. On cooling, a sequence of a nematic phase, three consecutive SmC phases and a DC phase were observed. We denoted these synclinic smectic $\mathrm{C}$ phases as the $\mathrm{SmC}_{\mathrm{s} 1}, \mathrm{SmC}_{\mathrm{s} 2}$ and $\mathrm{SmC}_{\mathrm{s} 3}$, respectively, on cooling. The DC phase is stable down to room temperature and crystallises on subsequent heating. On DSC thermograph the crystallisation of the DC phase takes place at about $85^{\circ} \mathrm{C}$ and is present in a form of the opposite peak on the second heating curve (Fig. 1a). On further heating, the crystal phase $(\mathrm{Cr})$ transforms to the $\mathrm{SmC}$ at $102^{\circ} \mathrm{C}$ and at $107^{\circ} \mathrm{C}$ the phase transition to the isotropic phase takes place. We will describe all observed mesophases later. On changing the positions of the azo and ester linking group in compound Ic, the mesomorphic behaviour completely disappeared. For compound Id with the azo group in both the elongating side arms, a sequence of two monotropic mesophases has been observed on cooling from the isotropic liquid. Namely, a narrow temperature interval of a nematic phase is followed by a smectic C phase (Fig. 2).

Textures and their features under the applied electric field and at various temperatures were observed using a polarizing optical microscope. For compound Id, a very narrow nematic phase is observed above the tilted smectic phase (Fig. 2a). For all studied compounds from series I, the observed smectic phases reveal broken fan-shaped texture (for illustration see Fig. $2 \mathrm{~b}$ for Id). The extinction position of all smectic mesophases is inclined from the layer normal by an angle of about 45 degrees, which provides evidence for the synclinic character of SmC phases. For compound $\mathbf{I b}$, we have observed a sequence of three $\mathrm{SmC}_{\mathrm{s}}$ mesophases and their planar textures are differing only slightly (see Fig. S1 in ESI†). On the other hand, homeotropic textures are not so uniform and reveal specific features for various $\mathrm{SmC}_{\mathrm{s}}$ phases of $\mathbf{I b}$. In Fig. $3 \mathrm{a}$ a phase transition from nematic to smectic phase is shown and we can observe "transition bars", which for calamitic LC compounds can accompany $\mathrm{N}-\mathrm{SmC}$ phase transition. ${ }^{32}$ Fig. $3 \mathrm{~b}$ and $\mathrm{c}$ show the schlieren texture in the $\mathrm{SmC}_{\mathrm{s} 1}$ and the $\mathrm{SmC}_{\mathrm{s} 2}$ phase, respectively. The lines appearing in the $\mathrm{SmC}_{\mathrm{s} 2}$ phase can be connected with undulations or defects arising in smectic planes. In Fig. 3d the texture in the $\mathrm{SmC}_{\mathrm{s} 3}$ phase is depicted.

For all compounds of series I, no response to the applied electric field was obtained in the observed $\mathrm{SmC}_{\mathrm{s}}$ mesophases, which provided further evidence on their non-polar character. Due to the narrow range of the $\mathrm{SmC}_{\mathrm{s} 3}$ phase exhibited by $\mathbf{I b}$, we 
Table 1 Mesomorphic properties of materials of series I and II

\begin{tabular}{|c|c|c|c|c|}
\hline Comp. & $\mathrm{X}$ & $\mathrm{Y}$ & Heating & Cooling \\
\hline Ia & $\mathrm{COO}$ & OOC & Cr 102 [38.0] Iso & Iso $97[12.4] \mathrm{SmC}_{\mathrm{s}} 95[21.9] \mathrm{Cr}$ \\
\hline Ib & $\mathrm{COO}$ & $\mathrm{N}=\mathrm{N}$ & DC $85[26.3]$ & Iso $106[0.92] \mathrm{N} 105[4.8] \mathrm{SmC}_{\mathrm{s} 1} 92[0.11] \mathrm{SmC}_{\mathrm{s} 2}$ \\
\hline Ic & $\mathrm{N}=\mathrm{N}$ & OOC & Cr 115 [60.4] Iso & Iso $108[59.4] \mathrm{Cr}$ \\
\hline Id & $\mathrm{N}=\mathrm{N}$ & $\mathrm{N}=\mathrm{N}$ & Cr 116 [91.7] Iso & Iso $117\left[{ }^{*}\right] \mathrm{N} 116[6.5] \mathrm{SmC}_{\mathrm{s}} 107[49.8] \mathrm{Cr}$ \\
\hline IIa & $\mathrm{COO}$ & OOC & Cr $107[41.2]$ Iso & Iso $105[24.4] \mathrm{SmC}_{\mathrm{a}} \mathrm{P}_{\mathrm{A}} 96[13.5] \mathrm{Cr}$ \\
\hline IId & $\mathrm{N}=\mathrm{N}$ & $\mathrm{N}=\mathrm{N}$ & Cr 116 [61.6] Iso & Iso $111[55.7] \mathrm{Cr}$ \\
\hline
\end{tabular}

${ }^{a}$ The phase transition were taken from the second heating and cooling runs at a rate of $5 \mathrm{~K} \mathrm{~min}^{-1}$. Phases are abbreviated: SmC $\mathrm{s}_{\mathrm{s}}-\mathrm{synclinic}$ smectic phase; $\mathrm{SmC}_{\mathrm{a}} \mathrm{P}_{\mathrm{A}}$ - anticlinic antiferroelectric SmC phase; Iso - isotropic liquid; $\mathrm{Cr}$ - crystalline phase; DC - dark conglomerate phase. ${ }^{*}-$ Iso- $\mathrm{N}$ enthalpy could not be separated from $\mathrm{N}-\mathrm{SmC}_{\mathrm{s}}$ enthalpy. Temperature is given in ${ }^{\circ} \mathrm{C}$ and phase transition enthalpy in $\mathrm{kJ} \mathrm{mol}^{-1}$.

were not able to determine its response to the applied electric field. However, the textures of all three consecutive $\mathrm{SmC}_{\mathrm{s}}$ phases are very similar and thus we assume that also the low temperature $\mathrm{SmC}_{\mathrm{s} 3}$ phase is of non-polar character. This result has further been supported by the dielectric spectroscopy measurements, see below.

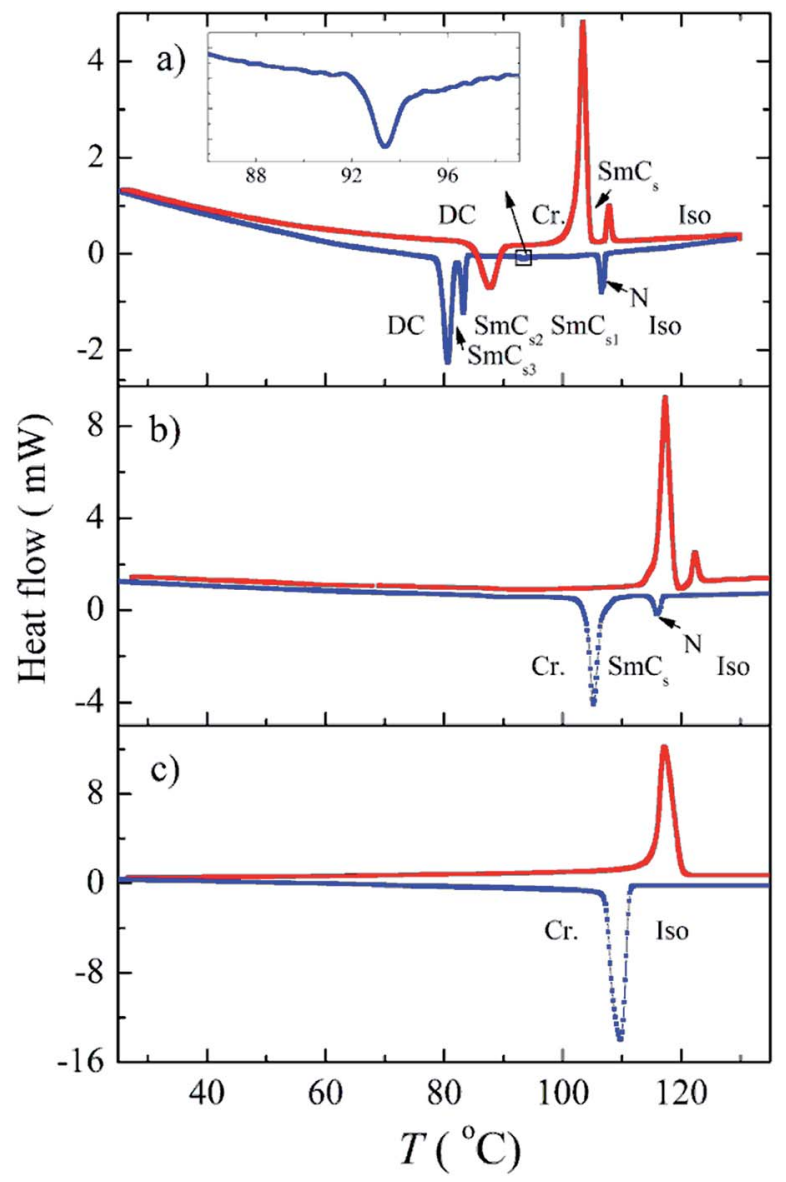

Fig. 1 DSC thermographs for compounds (a) Ib, (b) Id and (c) Ild. The inset in the figure (a) shows the phase transition from $\mathrm{SmC}_{\mathrm{S} 1}$ to $\mathrm{SmC}_{\mathrm{S} 2}$ taken on cooling, marked with an arrow. The red upper curves show the second heating run, the lower blue lines show the second cooling, taken at a rate of $5 \mathrm{~K} \mathrm{~min}^{-1}$.
In case of compound $\mathbf{I b}$, on further cooling from the $\mathrm{SmC}_{\mathrm{s} 3}$ phase, a highly viscous optically isotropic phase appears (Fig. 4b). Rotating the analyzer by a small angle leads to the appearance of dark and bright domains. Rotating the analyzer in the opposite direction reverses the dark and bright domains (Fig. 4a and c), while rotating the sample itself under crossed polarizers does not lead to any change in the dark texture. The overall distribution of the dark and bright domains is about $1: 1$ in both cases. This indicates that the domains are chiral with opposite handedness, which is a typical feature of chiral DC phases. ${ }^{13}$

The dielectric properties of $\mathbf{I b}$ were investigated within the broad temperature interval of all mesophases. Fig. 5 shows the real, $\varepsilon^{\prime}$, and imaginary, $\varepsilon^{\prime \prime}$, part of permittivity with respect to the temperature, $T$, and frequency. There is no distinct mode, which can be attributed to the polar arrangement. The values of permittivity are rather small, which support the idea of the nonpolar character of the observed $\mathrm{SmC}_{\mathrm{s}}$ mesophases. We can identify the phase transition temperatures, which are connected with small step-like changes of the real part of permittivity, $\varepsilon^{\prime}$. On the other hand, the imaginary part of permittivity reveals anomalies at the phase transition temperatures. In Fig. 5 these anomalies are marked by arrows. We can speculate that it corresponds to director fluctuations, which are more intensive in the vicinity of the phase transition. We can expect that in the

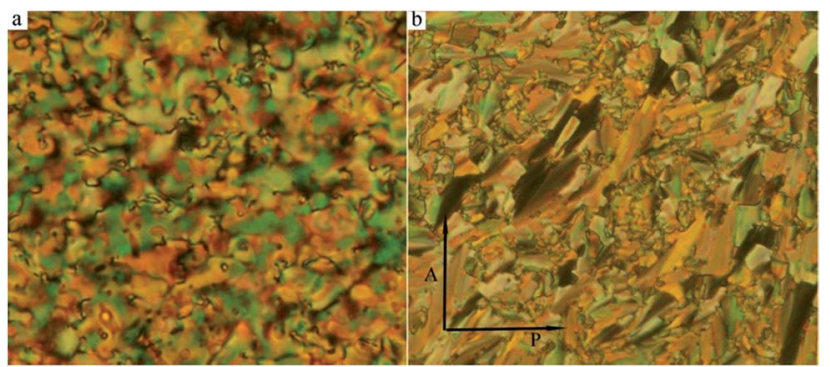

Fig. 2 Planar texture of compound Id at different temperature observed by polarizing microscope (a) in the $\mathrm{N}$ phase at $T=116^{\circ} \mathrm{C}$ and (b) in the $\mathrm{SmC}_{\mathrm{s}}$ phase at $T=110{ }^{\circ} \mathrm{C}$. The width of the figure corresponds to $200 \mu \mathrm{m}$. Orientation of the crossed polarisers $(A, P)$ is marked. 


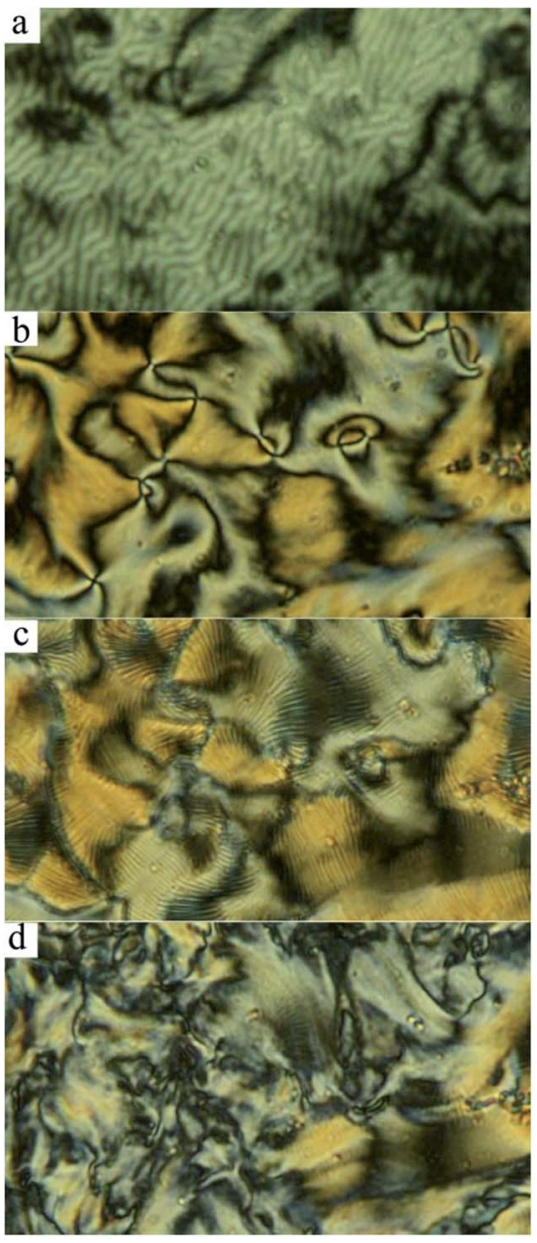

Fig. 3 Homeotropic texture for compound $\mathrm{Ib}(\mathrm{a})$ at the $\mathrm{N}-\mathrm{SmC} \mathrm{C}_{\mathrm{s} 1}$ phase transition at $T=105^{\circ} \mathrm{C}$, (b) in $\mathrm{SmC}_{\mathrm{s} 1}$ phase at $T=100{ }^{\circ} \mathrm{C}$, (c) in the $\mathrm{SmC}_{\mathrm{s} 2}$ phase at $T=86^{\circ} \mathrm{C}$ and (d) in the $\mathrm{SmC}_{\mathrm{s} 3}$ phase at $T=81^{\circ} \mathrm{C}$. The width of figures corresponds to $250 \mu \mathrm{m}$.

observed non-polar $\mathrm{SmC}_{\mathrm{s}}$ mesophase the bent-core molecules freely rotate along their molecular axis with rather high frequency and this molecular mode contributes mostly at the phase transitions. The values of permittivity are rather small, which support the idea of the non-polar character of the observed $\mathrm{SmC}_{\mathrm{s}}$ mesophases. On the other hand, we can identify the phase transitions because they are connected with molecular fluctuations. We can speculate that the bent-core molecules freely rotate along their molecular axis and this motion contributes mostly at the phase transitions.

X-ray scattering measurements were conducted for compound Ib as it shows the interesting phase sequence of nematic and different SmC phases ending with the DC phase. Due to the very narrow range of its existence $\sim 1 \mathrm{~K}$, it was not possible to carry out XRD investigations of the nematic phase. However, within all smectic phases, the X-ray intensity exhibited a sharp peak at small scattering angles and a diffuse maximum in the wide angle region (Fig. 6a for Ib in the $\mathrm{SmC}_{\mathrm{s} 1}$ phase). The layer spacing, $d$, can be established from the position of the intensity maximum at small scattering angles. The diffuse scattering peak at wide angles corresponds to the
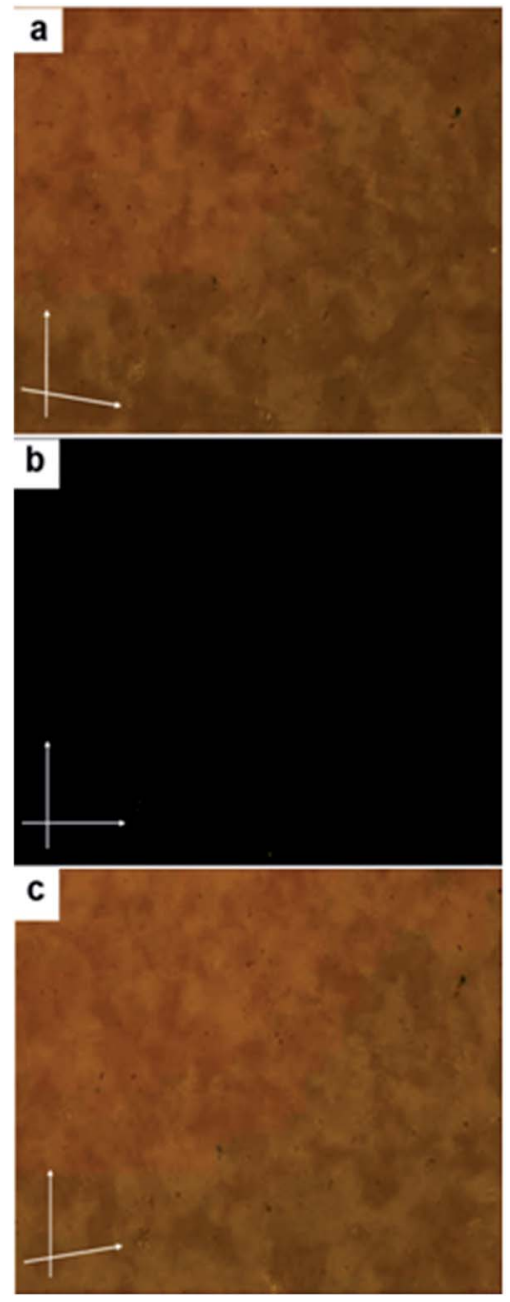

Fig. 4 Textures of the $\mathrm{DC}$ phase of compound $\mathrm{lb}$ at $T=50^{\circ} \mathrm{C}$ : (a) after rotating the analyzer by $10^{\circ}$ from the crossed position with respect to the polarizer in clock-wise direction; (b) under crossed polarizers and (c) in anticlockwise direction, showing dark and bright domains, indicating the presence of areas with opposite chirality sense.

average distance between molecules $\approx 4.5 \AA$. For compound Ib the corresponding $d$ value has been found $d=47.8 \AA$ at $T=$ $100{ }^{\circ} \mathrm{C}$, which is substantially smaller than the molecular length, $l$, calculated in $a b$ initio calculations $l=56.3 \AA$. Comparing X-ray data with calculations, the tilt angle can be estimated to be about 32 degrees. We confirmed a lamellar character of the SmC mesophases observed on cooling from the isotropic phase for other compounds. Due to the monotropic character of the mesophases and their fast crystallisation, it was not possible to finish detailed X-ray measurements.

X-ray investigations in the DC phase of Ib (Fig. 6b) show an intense layer signal with corresponding weak harmonic reflections in small and medium angle region. All scatterings form closed rings with uniform intensity distribution, which provides evidence for the disordered meso-structure of the DC phase. The observed layer thickness points to tilted organization within layer with a molecular tilt angle of about $29^{\circ}$. Such a value is typical neither for DC sponge phases nor for helicalnanofilament phase ( $\mathrm{B}_{4}$ phase). Furthermore, the broad signal 

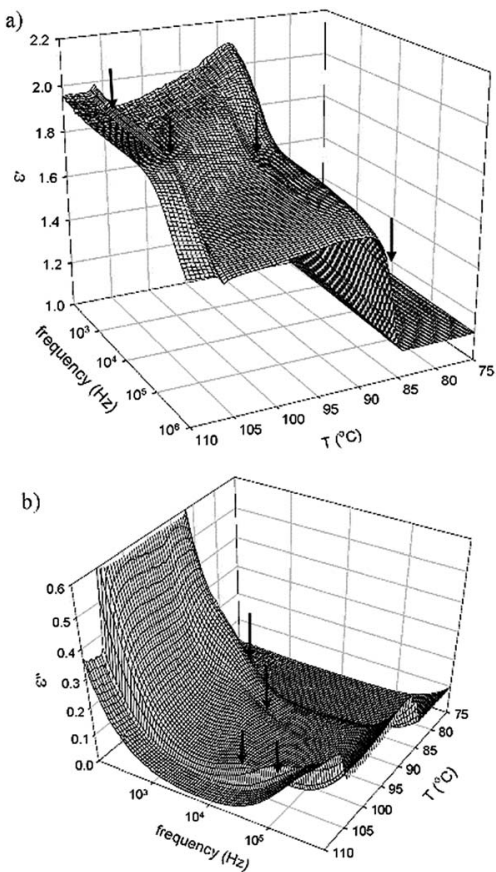

Fig. 5 3-Dimensional plots of the real, $\varepsilon^{\prime}$, and imaginary, $\varepsilon^{\prime \prime}$, part of permittivity with respect to the temperature, $T$, and frequency for $\mathrm{lb}$. The arrows mark phase transition.
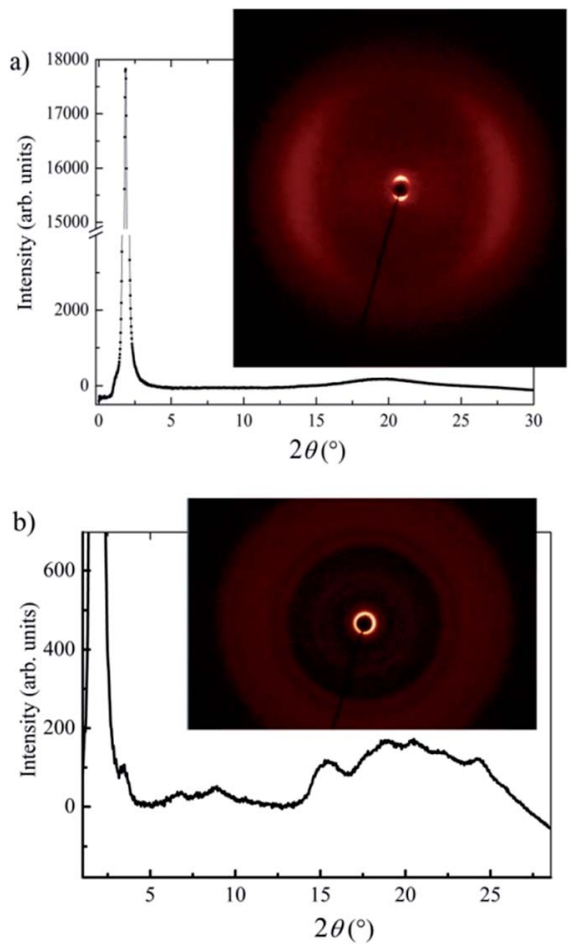

Fig. $6 \mathrm{X}$-ray intensity versus scattering angle for compound lb: (a) at $T=$ $100^{\circ} \mathrm{C}$ in the $\mathrm{SmC}_{\mathrm{s} 1}$ phase and (b) at $T=70^{\circ} \mathrm{C}$ in the $\mathrm{DC}$ phase. The insets show the corresponding $2 \mathrm{D} \mathrm{X}$-ray patterns at the indicated temperature.

in the wide angle region could be fitted to six maxima in the $2 \theta$ range between 15 and $26^{\circ}$ (Fig. 6b). This pattern clearly excludes fluid sponge phases that show only a very diffuse wide angle scattering. However, such reflections can not be ascribed to a $\mathrm{B}_{4}$ phase, which typically shows the reflection as sharp separate signals. These results indicate that the DC phase under investigation is similar to the recently described new sub-type of a DC phase exhibited by related 4-methylresorcinol-based materials with one inverted ester ${ }^{24}$ The reflections in small and medium region appear at very similar positions. The wide angle region shows more diffuse pattern with two more maxima, which could arise from slightly different molecular packing within the studied DC phase. Therefore, inverting the direction of the ester group retains the DC phase but slightly change its fine structure.

\section{Series II}

The mesomorphic properties of series II differ from those of series I. This change probably results from the different position of the lateral methyl group at the apex of the bent-core mesogen. In case of compound IIa with all ester linkages, a monotropic $\mathrm{SmC}_{\mathrm{a}} \mathrm{P}_{\mathrm{A}}$ phase was identified (see Fig. $7 \mathrm{~d}$ ). Surprisingly, the introduction of the azo group in the elongating side arm connected to the carboxylic unit of the central core (IIb) led to the complete loss of mesomorphic behaviour. When changing the positions of the azo and ester linking groups (IIc), the monotropic $\mathrm{SmC}_{\mathrm{a}} \mathrm{P}_{\mathrm{A}}$ phase was restored. Compound IId possessing two azo units in the structure was crystalline only.

Compounds IIa and IIc showed two peaks at half-period under the applied triangular field (Fig. 7a and b). The switching current documents the antiferroelectric nature of the studied mesophases. Based on this observation, the mesophase for both IIa and IIc was assigned as $\mathrm{SmC}_{\mathrm{a}} \mathrm{P}_{\mathrm{A}}$. Due to relatively fast crystallisation of the materials under the applied electric field, we were able to record only changes of planar textures of IIa (Fig. 7c-e).
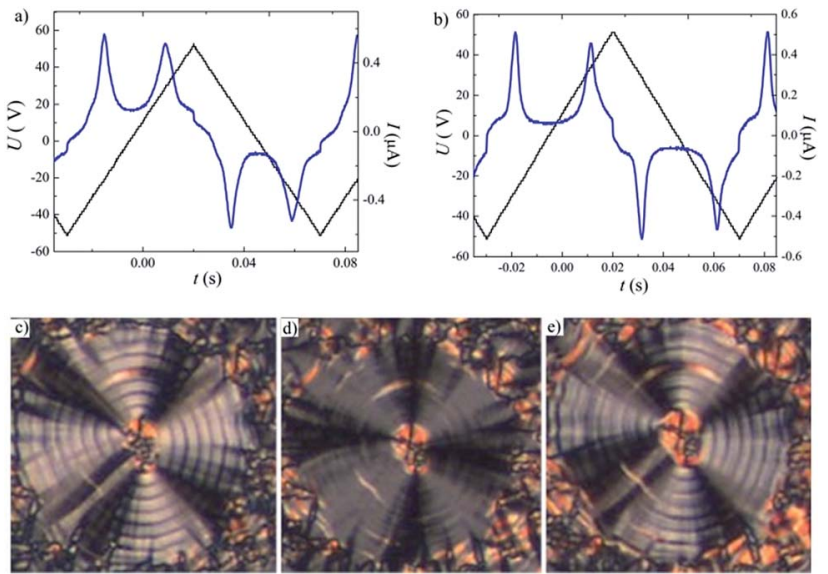

Fig. 7 Switching current response curves recorded by applying a triangular wave voltage in the $\mathrm{SmC}_{\mathrm{a}} \mathrm{P}_{\mathrm{A}}$ phase for compounds: (a) Ila at $103^{\circ} \mathrm{C}$ and (b) Ilc $99^{\circ} \mathrm{C}$; ( $\mathrm{c}-\mathrm{e}$ ) optical textures in the $\mathrm{SmC}_{\mathrm{a}} \mathrm{P}_{\mathrm{A}}$ phase for compound Ila at $102^{\circ} \mathrm{C}$ under an applied DC voltage between crossed polarizers in (c) field induced $\mathrm{SmC}_{\mathrm{S}} \mathrm{P}_{\mathrm{F}}$ state at $+10 \mathrm{~V}$, (d) in the $\mathrm{SmC}_{\mathrm{a}} \mathrm{P}_{\mathrm{A}}$ state at $V=0$ after switching off the field and (e) the field induced $\mathrm{SmC}_{\mathrm{s}} \mathrm{P}_{\mathrm{F}}$ state at $-10 \mathrm{~V}$. 
The dielectric spectroscopy for compound IIa and IIc has been performed and a distinct mode observed in the $\mathrm{SmC}_{\mathrm{a}} \mathrm{P}_{\mathrm{A}}$ phase on cooling from the isotropic phase. 3-Dimensional plot of the real and imaginary parts of the permittivity for IIa is illustrated in Fig. 8. The observed mode completely disappears in the isotropic as well as in the crystalline phase, so we can conclude that it is connected with collective fluctuations of molecules. Such mode is very often observed for SmCP phases and is explained by vibrations of tilted molecules in polar ordered systems with interactions between neighbouring layers. ${ }^{33}$

\section{Photochemical properties}

The presence of the azo units in the investigated BCLCs allows the study of photoisomerisation under UV light irradiation. This phenomenon has been reported before for similar azobenzene containing BCLCs in solutions using UV-Vis spectrometry. ${ }^{13}$ However, herein we study this process using ${ }^{1} \mathrm{H}$ NMR spectroscopy. This method allows us to determine the amount of $Z$-isomer formed upon UV irradiation of the predominant $E$-isomer of an azo group containing materials. Moreover, this method is suitable for the observation of the thermal relaxation of the formed $Z$-isomer back to the more stable $E$-isomer in the dark. It is evident that with the increasing number of azo units present in a molecule, the ${ }^{1} \mathrm{H}$ NMR spectrum of such a compound gains in complexity. In case of two azo groups, the formation of four different chemical species can
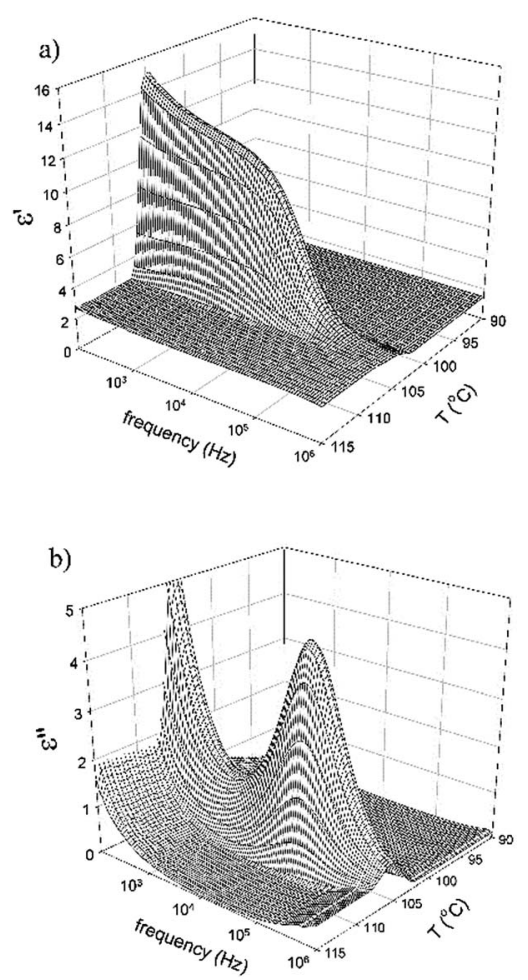

Fig. 8 3-Dimensional plot of (a) the real part of permittivity, $\varepsilon^{\prime}$, and (b) the imaginary part of permittivity, $\varepsilon^{\prime \prime}$, versus temperature, $T$, and frequency for Ila.

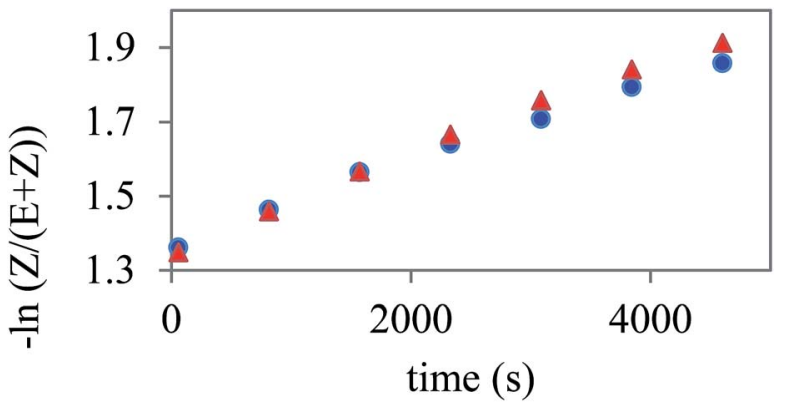

Fig. 9 The time dependent decrease of the concentration of $Z$-isomer in the solution of $\mathrm{Ib}$ (triangles) and Illb (dots) depicted in the logarithmic scale.

be envisioned for a non-symmetrical bent-core compound. Therefore, we decided to study substances with one azo group in the elongating side arms, namely polymorphic Ib and crystalline IIb.

From the acquired ${ }^{1} \mathrm{H}$ NMR spectra (see Fig. S3 and S4 $\dagger$ ), thermal relaxation back to the thermodynamically more stable $E$-isomer from the $Z$-isomer formed by UV-irradiation is evident. The relaxation rate constants determined from the slope of the decrease was $1.2510^{-4} \mathrm{~s}^{-1}$ for Ib and $1.0810^{-4} \mathrm{~s}^{-1}$ for IIb (Fig. 9). This result indicates a slightly lower flexibility of compound IIb, which may be caused by the steric influence of the lateral substituent in position 6 on the central core. This feature can be used for the design of the next generation of slow relaxing photosensitive bent-core compounds. Such compounds with very stable $Z$-isomer can be then used for optical data storage or photo-alignment of LC matrices.

\section{$A b$ initio calculations}

The differences in mesomorphic properties can also be explained on the basis of a preferred molecular conformation. The conformers with minimum energy of Ib showing three consecutive non-polar SmC phases and a DC phase, and IIc exhibiting the $\mathrm{SmC}_{\mathrm{a}} \mathrm{P}_{\mathrm{A}}$ phase were calculated using density functional theory method at B3LYP 3-21g level in Gaussian software. Despite the fact that the calculations were performed

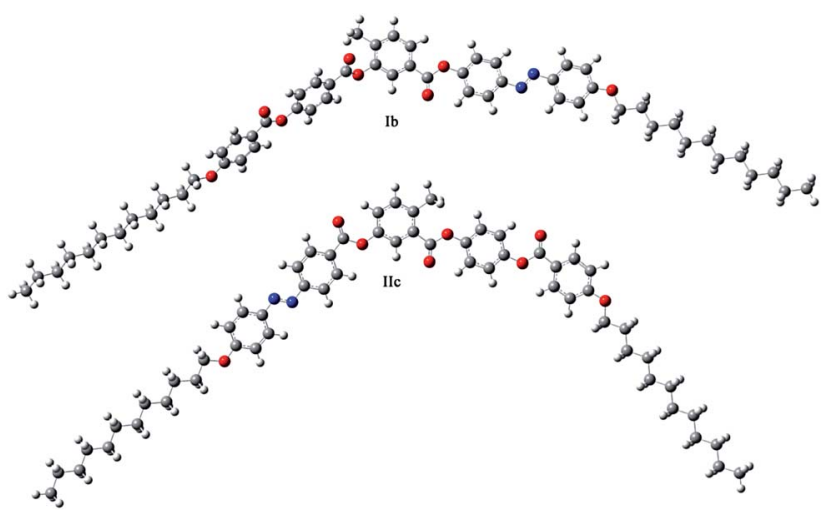

Fig. 10 Conformers with minimum energy of Ib and Ilc obtained by $a b$ initio calculations. 
for a single molecule in vacuum, the conformers with minimum energy showed strong preference of Ib towards more linear arrangement, while IIc prefers rather a bent molecular shape (Fig. 10). The favourable molecular shapes correspond well with the formed mesophases; more linear molecules tend to organize in mesophases typical for rod-like mesogens, and bent molecules form mesophases typical of bent-core molecules.

\section{Conclusions}

New photosensitive BCLCs based on 4- and 6-methyl substituted 3-hydroxybenzoic acid have been synthesised and studied. We show that the position of the lateral substituent on the central core with respect to the position of the azo group-bearing elongating side arm strongly influences physical properties of the materials. For 4-methyl substituted materials of series I, generally, non-polar synclinic SmC phases have been identified. In case of $\mathbf{I b}$, rich polymorphism has been observed on cooling from the isotropic phase, namely, nematic phase followed by three synclinic smectic phases and ending with a dark conglomerate phase (DC phase). None of the $\mathrm{SmC}_{\mathrm{s}}$ phase revealed switching under the applied electric field. Non-polar character is further supported by the dielectric spectroscopy data. In details, we have described the disordered meso-structure of the DC phase, which exists below the $\mathrm{SmC}_{\mathrm{s}}$ phases at room temperature. It was confirmed that this DC phase has a different structure from those of $\mathrm{B}_{4}$ phases and DC sponge phases, but very similar to the DC phases of the related 4-methylresorcinol derived BCLCs. This indicates that inverting the direction of one ester group in the side arm of the bent-core mesogen changes the fine structure of the formed DC phase, thus, adding a new subtype to the family of these phases.

The synclinic SmC phases observed for series I were replaced for series II derivatives either by anticlinic polar SmC phases $\left(\mathrm{SmC}_{\mathrm{a}} \mathrm{P}_{\mathrm{A}}\right.$ phases) or crystalline phases. The formation of the $\mathrm{SmC}_{\mathrm{a}} \mathrm{P}_{\mathrm{A}}$ phase (materials IIa and IIc) is probably due to the preferred bent molecular shape of the materials. The absence of mesomorphic behaviour in the case of IIb and IId can be explained by the limited flexibility of the side chain next to the lateral substituent. The negative effect of a larger substituent in the vicinity of the carboxylic unit on the 3-hydroxybenzoic acidbased materials in combination with less flexible side chains has recently been described. ${ }^{26}$ It is reasonable to assume that the introduction of the azo unit further limits the overall flexibility of the substance required for efficient molecular packing within a mesophase.

In conclusion, the mesomorphic properties of the presented materials are mainly influenced by the mutual position of the photosensitive unit and the lateral substituent. Thus, proper molecular design may provide materials exhibiting mesomorphic properties typical of calamitic materials or bent-core liquid crystals. Slower thermal relaxation of UV-induced $Z$-isomer of azo-containing bent-core materials may be beneficial for optical data storage and related applications.

\section{Conflict of interest}

There are no conflicts of interest to declare.

\section{Acknowledgements}

This work was supported by Czech Science Foundation (project No. 16-12150S).

\section{Notes and references}

1 D. R. Link, G. Natale, R. Shao, J. E. Maclennan, N. A. Clark, E. Körblova and D. M. Walba, Science, 1997, 278, 1924.

2 T. Niori, T. Sekine, J. Watanabe, T. Furukawa and H. Takezoe, J. Mater. Chem., 1996, 6, 1231.

3 I. Dierking, Angew. Chem., Int. Ed., 2010, 49, 29.

4 R. A. Reddy and C. Tschierske, J. Mater. Chem., 2006, 16, 907.

5 C. Tschierske, Angew. Chem., Int. Ed., 2013, 52, 8828.

6 J. Etxebarria and M. Blanca Ros, J. Mater. Chem., 2008, 18, 2919.

7 W. Iglesias, N. L. Abbott, E. K. Mann and A. Jákli, ACS Appl. Mater. Interfaces, 2012, 4, 6884.

8 M. Nagaraj, Y. P. Panarin, J. K. Vij, C. Keith and C. Tschierske, Appl. Phys. Lett., 2010, 97, 213505.

9 D. Vorländer, Ber. Dtsch. Chem. Ges. A, 1929, 62, 2831.

10 S. Kawata and Y. Kawata, Chem. Rev., 2000, 100, 1777.

11 P. Rochon, E. Batalla and A. Natansohn, Appl. Phys. Lett., 1995, 66, 136.

12 O. Yaroshchuk and Y. Reznikov, J. Mater. Chem., 2012, 22, 286.

13 M. Alaasar, Liq. Cryst., 2016, 43, 2208.

14 N. G. Nagaveni, P. Raghuvanshi, A. Roy and V. Prasad, Liq. Cryst., 2013, 40, 1238.

15 N. G. Nagaveni, A. Roy and V. Prasad, J. Mater. Chem., 2012, 22, 8948.

16 V. Prasad, Liq. Cryst., 2001, 28, 145.

17 M. Alaasar, M. Prehm, M. Nagaraj, J. K. Vij and C. Tschierske, Adv. Mater., 2013, 25, 2186.

18 M. Alaasar, M. Prehm, K. May, A. Eremin and C. Tschierske, Adv. Funct. Mater., 2014, 24, 1703.

19 M. Alaasar, M. Prehm, M.-G. Tamba, N. Sebastián, A. Eremin and C. Tschierske, ChemPhysChem, 2016, 17, 278.

20 M. Alaasar, M. Prehm and C. Tschierske, Liq. Cryst., 2013, 40, 656.

21 M. Alaasar, M. Prehm and C. Tschierske, Chem. Commun., 2013, 49, 11062.

22 M. Alaasar, M. Prehm and C. Tschierske, RSC Adv., 2016, 6, 82890.

23 M. Alaasar, M. Prehm and C. Tschierske, Chem.-Eur. J., 2016, 22, 6583.

24 M. Alaasar, M. Prehm, M. Brautzsch and C. Tschierske, J. Mater. Chem. C, 2014, 2, 5487.

25 V. Prasad, S.-W. Kang, X. Qi and S. Kumar, J. Mater. Chem., 2004, 14, 1495.

26 N. Trisovic, J. Antanasijevic, T. Toth-Katona, M. Kohout, M. Salamonczyk, S. Sprunt, A. Jakli and K. Fodor-Csorba, RSC Adv., 2015, 5, 64886. 
27 M. Kohout, V. Kozmík, M. Slabochová, J. Tůma, J. Svoboda, V. Novotná and D. Pociecha, Liq. Cryst., 2015, 42, 87.

28 J. Tůma, M. Kohout, J. Svoboda, V. Novotná and D. Pociecha, Liq. Cryst., 2016, 43, 1889.

29 M. Alaasar, M. Prehm, M. Brautzsch and C. Tschierske, Soft Matter, 2014, 10, 7285.

30 J. M. El Khoury, X. Zhou, L. Qu, L. Dai, A. Urbas and Q. Li, Chem. Commun., 2009, 2109.
31 M. Kohout, J. Svoboda, V. Novotná, D. Pociecha, M. Glogarová and E. Gorecka, J. Mater. Chem., 2009, 19, 3153. 32 D. Demus and L. Richter, Textures of Liquid Crystals, VEB Deutscher Verlag, Leipzig, 1978.

33 A. V. Emelyanenko and M. A. Osipov, Phys. Rev. E: Stat., Nonlinear, Soft Matter Phys., 2004, 70, 021704. 